\title{
Nocturnal Gastroesophageal Reflux: Assessment and Clinical Implications
}

\author{
Kwang Jae Lee \\ Department of Gastroenterology, Ajou University School of Medicine, Suwon, Gyeonggi-do, Korea
}

\author{
Article: Nocturnal gastroesophageal reflux revisited by impedance-pH monitoring \\ Fornari F, Blondeau K, Mertens V, Tack J, Sifrim D \\ (J Neurogastroenterol Motil 2011;17:148-157)
}

Nocturnal gastroesophageal reflux has been shown to be associated with the more severe forms of gastroesophageal reflux disease (GERD), particularly with atypical/extraesophageal manifestations as well as complications of mucosal damage, such as esophagitis and stricture, Barrett's esophagus and esophageal adenocarcinoma. ${ }^{1,2}$ Heartburn during sleep and sleep disturbances are common manifestations of nocturnal gastroesophageal reflux. In a population-based telephone interview survey of 1,000 adults, $13 \%$ of the respondents reported experiencing heartburn only during nighttime and $65 \%$ experienced heartburn on both day and night. Altogether $79 \%$ of heartburn sufferers reported nocturnal heartburn. ${ }^{3}$ Farup and colleagues ${ }^{4}$ reported that $74 \%$ of GERD patients had nocturnal reflux symptoms and $54 \%$ experienced heartburn that awakened them from sleep. In contrast, in a community-based study by Locke and colleagues, ${ }^{5} 47 \%$ and $34 \%$ of GERD sufferers reported nocturnal heartburn and nocturnal acid regurgitation, respectively. About one-quarter of subjects with sleep disturbances report heartburn during sleep. ${ }^{6}$ Thus, a better understanding of nocturnal gastroesophageal reflux is of significant diagnostic and management implications.
In the current issue of the Journal, Fornari et al re-assessed nocturnal gastroesophageal reflux using impedance-pH monitoring in order to elucidate the prevalence and characteristics of nocturnal reflux in healthy subjects and GERD patients. They found that GERD patients had more nocturnal reflux events than healthy subjects. Of nocturnal reflux events, $57 \%$ were weakly acidic reflux, which predominated in the last 3 hours of the night. In this study, they demonstrated that nocturnal reflux reached the proximal esophagus more often in GERD patients than in healthy subjects and described prolonged chemical clearance associated with less esophageal activity in GERD patients. Reflux episodes are divided into daytime and nighttime events. Nighttime gastroesophageal reflux is of clinical importance because it is associated with the development of complicated GERD, extraesophageal manifestations of GERD and a variety of sleep disturbances. In addition, patients with nocturnal GERD symptoms have a substantially diminished quality of life as compared with individuals without nocturnal GERD symptoms. ${ }^{4}$ Nocturnal gastroesophageal reflux is an underappreciated clinical challenge in many patients with GERD. Previous studies assessing

Received: February 16, 2011 Revised: None Accepted: February 18, 2011

(c) This is an Open Access article distributed under the terms of the Creative Commons Attribution Non-Commercial License (http://creativecommons. org/licenses/by-nc/3.0) which permits unrestricted non-commercial use, distribution, and reproduction in any medium, provided the original work is properly cited.

*Correspondence: Kwang Jae Lee, MD, PhD

Department of Gastroenterology, Ajou University Hospital, Ajou University School of Medicine, 164, Worldcup-ro, Yeongtong-gu, Suwon, Gyeonggi-do 443-721, Korea

Tel: +82-31-219-5102, Fax: +82-31-219-5999, E-mail: kjleemd@hotmail.com

Financial support: None.

Conflicts of interest: None. 
nocturnal reflux have addressed on acid events. Conventional esophageal $\mathrm{pH}$ monitoring is not able to detect all gastroesophageal reflux events, particularly when little or no acid is present in the refluxate. Esophageal impedance-pH monitoring can detect non-acid reflux as well as acid reflux, and increase the sensitivity for detection of reflux episodes. ${ }^{7}$ Non-acid reflux includes weakly acidic and weakly alkaline reflux. The number of acid reflux events and the total percentage of esophageal $\mathrm{pH}<4$ are believed to be correlated to the degree of mucosal damage. However, the importance of non-acid reflux in the genesis of mucosal damage or symptoms has not been fully established. The results of the study by Fornari et al suggest possible involvement of weakly acidic reflux in the genesis of GERD symptoms or complications associated with nocturnal reflux. They showed that combined impedance-pH monitoring made it possible to identify more patients in whom gastroesophageal reflux was the cause of their nocturnal GERD symptoms. However, they did not evaluate the correlation of weakly acidic reflux with nocturnal symptoms, probably because of the difficulty in checking symptoms during sleep. The majority of reflux episodes during nighttime was weakly acidic in healthy subjects as well as in GERD patients. Thus, further investigation on the association of nocturnal symptoms with weakly acidic reflux events is warranted.

In the study from Fornari et al, $43 \%$ of reflux episodes in GERD patients off proton pump inhibitor (PPI) therapy was acidic and $57 \%$ was weakly acidic. In general, the majority of episodes was acidic off PPI, which caused the majority of symptoms. On PPI, the majority of reflux episodes was weakly acidic and these were responsible for reflux symptoms occurring during the PPI therapy. ${ }^{8,9}$ Weakly alkaline reflux was very rare. ${ }^{8,9}$ The high predominance of weakly acidic reflux during the night suggests that nocturnal GERD symptoms are not well controlled by PPI therapy. PPIs are the mainstay of anti-secretory therapy for daytime and nighttime gastroesophageal reflux disease, but their effectiveness for nocturnal reflux may be limited by the characteristics of nocturnal reflux events. Given that acid can sensitize the esophagus to subsequent reflux episodes, a high dose PPI or addition of a histamine $\mathrm{H}_{2}$-receptor antagonist at bedtime to PPI therapy seems logical. However, if this is not helpful, the next choice is lacking. Drugs that effectively reduce the number of reflux episodes are not currently acceptable. Baclofen has unfavorable side effects and is not commonly used for the treatment of GERD. Anti-reflux surgery can reduce both acid and weakly acidic reflux episodes. However, it may also produce side effects such as dysphagia, the sensation of inability to belch, and severe symptoms of bloating and abdominal discomfort. Development of effective treatments is required for reducing excessive weakly acidic reflux events, through which is expected to be able to decrease nocturnal reflux.

The majority of the refluxate from the stomach is cleared from the esophagus by either primary or secondary peristalsis. The residual hydrogen in the esophagus is neutralized by salivary bicarbonate. ${ }^{10}$ Since swallowing ceases during sleep, primary peristalsis is not induced. Accordingly, secondary peristalsis stimulated by the reflux of gastric contents plays a main role in clearing the refluxate from the esophagus. Fornari et al demonstrated that post-reflux poor esophageal motor activity and prolonged acid clearance were associated with nocturnal reflux in GERD patients. This observation is in keeping with the previous finding that the triggering mechanism of secondary peristalsis was deteriorated in GERD patients. ${ }^{11}$ In addition, the effect of gravity in the recumbent position during sleep retards esophageal clearance. The cessation of swallowing during sleep also reduces esophageal clearance and impairs acid neutralization. Thus, nocturnal reflux is associated with prolonged acid contact with the mucosa, damaging to the esophageal mucosa. Furthermore, the reduced esophageal peristaltic activity may lead to proximal extent of the refluxate, which is also shown in the study from Fornari et al. This finding explains the association of atypical/extraesophageal manifestations with nocturnal reflux.

In conclusion, the study by Fornari et al has contributed to a better understanding of nocturnal gastroesophageal reflux by re-assessing nocturnal gastroesophageal reflux using esophageal impedance-pH monitoring in healthy subjects and GERD patients.

\section{References}

1. Cuttitta G, Cibella F, Visconti A, Scichilone N, Bellia V, Bonsignore G. Spontaneous gastroesophageal reflux and airway patency during the night in adult asthmatics. Am J Respir Crit Care Med 2000;161: 177-181.

2. Jacob P, Kahrilas PJ, Herzon G. Proximal esophageal pH-metry in patients with 'reflux laryngitis'. Gastroenterology 1991;100:305-310.

3. Shaker R, Castell DO, Schoenfeld PS, Spechler SJ. Nighttime heartburn is an under-appreciated clinical problem that impacts sleep and daytime function: the results of a gallup survey conducted on behalf of the American gastroenterological association. Am J Gastroenterol 2003;98:1487-1493.

4. Farup C, Kleinman L, Sloan S, et al. The impact of nocturnal symptoms associated with gastroesophageal reflux disease on health-related quality of life. Arch Intern Med 2001;161:45-52.

5. Locke GR 3rd, Talley NJ, Fett SL, Zinsmeister AR, Melton LJ. 
Prevalence and clinical spectrum of gastroesophageal reflux: a population-based study in Olmsted County, Minnesota. Gastroenterology 1997;112:1448-1456.

6. Fass R, Quan SF, Howard BV, et al. Predictors of heartburn during in a large prospective cohort study. Chest 2005;127:1658-1666.

7. Sifrim D, Holloway R, Silny J, et al. Acid, nonacid, and gas reflux in patients with gastro-oesophageal reflux disease during ambulatory 24-hour pH-impedance recordings. Gastroenterology 2001;120: 1588-1598

8. Mainie I, Tutuian R, Shay S, et al. Acid and non-acid reflux in patients with persistent symptoms despite acid suppressive therapy: a multicentre study using combined ambulatory impedance-pH monitoring. Gut 2006;5 5:1398-1402.

9. Zerbib F, Roman S, Ropert A, et al. Esophageal $\mathrm{pH}$-impedance monitoring and symptom analysis in GERD: a study in patients off and on therapy. Am J Gastroenterol 2006;101:1956-1963.

10. Helm JF, Dodds WJ, Pelc LR, Palmer DW, Hogan WJ, Teeter BC. Effect of esophageal emptying and saliva on clearance of acid from the esophagus. N Engl J Med 1984;310:284-288.

11. Schoeman MN, Holloway RH. Integrity and characteristics of secondary oesophageal peristalsis in patients with gastro-oesophageal reflux disease. Gut 1995;36:499-504. 